\title{
Systemic inflammatory response after bronchoalveolar lavage in critically ill patients
}

\author{
T.T. Bauer*, C. Arosio*, C. Montón*, X. Filella\#, A. Xaubet*, A. Torres*
}

Systemic inflammatory response after bronchoalveolar lavage in critically ill patients. T.T. Bauer, C. Arosio, C. Montón, X. Filella, A. Xaubet, A. Torres. (C)ERS Journals Ltd 2001

ABSTRACT: Bronchoscopic bronchoalveolar lavage (BAL) may be followed by a systemic inflammatory response. Previous reports have suggested pneumonia as a predisposing condition and systemic cytokines as possible mediators.

To test this hypothesis, systemic levels of interleukin (IL)-1ß, IL-6 and tumour necrosis factor-alpha (TNF- $\alpha$ ) were studied before and at $12 \mathrm{~h}$ and $24 \mathrm{~h}$ after bronchoscopically guided BAL in 30 mechanically ventilated patients (median age 67 (range 54-76) yrs, simplified acute physiology score II (SAPS II) 33 (12-56)), 20 of whom had pneumonia and 10 of whom were control patients without pneumonia. Arterial oxygen partial pressure to inspired oxygen fraction ratio $\left(\mathrm{Pa}_{\mathrm{a}} \mathrm{O}_{2} / \mathrm{F}, \mathrm{O}_{2}\right)$, body temperature, mean arterial pressure, and cardiac frequency were recorded. The majority of patients $(28 / 30,93 \%)$ received antibiotic treatment prior to the procedure.

$\mathrm{P}_{1}, \mathrm{O}_{2} / \mathrm{FI}, \mathrm{O}_{2}$ ratio was lower at $12 \mathrm{~h}$ compared to baseline in patients with pneumonia (baseline median 192 (range 65-256); $12 \mathrm{~h} 160(66-190) \mathrm{mmHg}, \mathrm{p}<0.001$ ) and

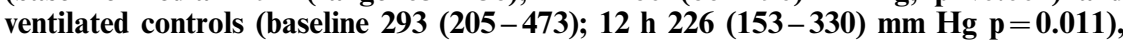
but returned to baseline levels at $24 \mathrm{~h}$ (pneumonia: $194(92-312), p=0.991$; controls: $309(173-487) \mathrm{mmHg}, p=0.785)$. No changes in other clinical variables were observed. Systemic TNF- $\alpha$ levels before BAL (pneumonia: $35(10-88)$; controls: $17(0-33)$ $\mathrm{pg} \cdot \mathrm{mL}^{-1}$ ) did not increase at $12 \mathrm{~h}$ (pneumonia: $35(0-64) ; \mathrm{p}=0.735$; controls: $16(0-21)$ $\mathrm{pg} \cdot \mathrm{mL}^{-1}, \mathrm{p}=0.123$ comparison to baseline) or $24 \mathrm{~h}$ (pneumonia: $31(0-36), \mathrm{p}=0.464$; controls: $\left.19(0-43) \mathrm{pg} \cdot \mathrm{mL}^{-1}, \mathrm{p}=0.358\right)$. No changes of IL-1 $\beta$ (baseline: pneumonia 0 $(0-13)$; controls $\left.1(0-32) \mathrm{pg} \cdot \mathrm{mL}^{-1}\right)$ or IL-6 (baseline: pneumonia, $226(9-4300)$; controls, $\left.53(0-346) \mathrm{pg} \cdot \mathrm{mL}^{-1}\right)$ were detected.

No deterioration of clinical variables and no increase in systemic cytokine release has been observed after bronchoalveolar lavage, in critically ill patients. The potential cytokine increase is probably too small, in relation to the pre-existing inflammatory response, to yield clinical significance in this population otherwise antibiotic therapy may have been protective.

Eur Respir J 2001; 17: 274-280.
*Institute of Pneumology and Thoracic Surgery, Hospital Clinic de Barcelona and ${ }^{\#}$ Biochemistry, Hospital Clinic, University of Barcelona, Barcelona, Spain.

Correspondence: A. Torres, Hospital Clínic de Barcelona, Institut de Pneumologia: Toràcica, Villarroel, 170 , 08036 Barcelona, Spain. Fax: + 34932275454

Keywords: Bronchoalveolar lavage diagnosis

intensive care unit

interleukins

inflammatory response

pneumonia

Received: March 232000

Accepted after revision September 29 2000

This work was supported by: Fondo de investigación Sanitaria (FIS) Grant \#: 98/1096, 1997, Suport dels Grups de Recerca (SGR) Grant \#: 00086, IDIBAPS, Comissió Interdepartmental de Recerca i Innovació Tecnológica (CIRIT, 1999), the European Respiratory Society (ERS), and the Bochumer Arbeitskreis für Peumologie und Allergologie (BAPA).
Fibreoptic procedures, and particularly bronchoalveolar lavage (BAL), are important diagnostic tools, and tolerance is generally good. Side effects such as serious arrhythmia, bleeding, pneumonia, or pneumothorax are rare [1] and acute haemodynamic effects are small even in critically ill intubated patients [2]. However, in some cases, BAL may be followed by myalgia, headache or even fever [3]. A systematic follow-up after bronchoscopically guided BAL suggested that this systemic inflammatory response, or sepsis-like syndrome, is caused by a proinflammatory cytokine release [4]. This study in noncritically ill patients, however, excluded patients with pneumonia, and did not assess the bacterial burden of the lungs. Translocation of bacterial products [5] or even entire micro-organisms [6] from the lungs to the bloodstream, however, may play a crucial role for the pyrogenic response after BAL, particularly in the presence of mechanical ventilation.

Systemic cytokine levels have therefore been studied after bronchoscopically guided BAL in mechanically ventilated patients, with and without pneumonia.

\section{Materials and methods}

This trial was conducted in an 850-bed tertiary care hospital between January 11995 and December 31 1997. All patients on ventilatory support for more than $48 \mathrm{~h}$ in one respiratory intensive care unit (RICU) were eligible for the study. Patients were included consecutively if they fulfilled clinical criteria of pneumonia: presence of new infiltrates on the chest radiograph and two of the following criteria: fever $\geqslant 38.3^{\circ} \mathrm{C}$, purulent secretions, leukocytosis $\left(\geqslant 12,000 \cdot \mathrm{mm}^{-3}\right)$ or leukopenia $\left(\leqslant 4,000 \cdot \mathrm{mm}^{-3}\right)$. Pneumonia was classified as community-acquired (occuring $<72 \mathrm{~h}$ into stay) or nosocomial $(\geqslant 72 \mathrm{~h})$. The ventilated control group without pneumonia included patients who met the following criteria: 1) mechanical ventilatory support for more than $48 \mathrm{~h}$; 
2) absence of any infectious process; or 3) absence of any of the criteria of the pneumonia group. Bronchoscopy was indicated for other reasons (e.g. tube malposition, minor haemoptysis or visual inspection of the tracheobronchial tree) in patients without pneumonia.

Exclusion criteria were: 1) unstable clinical condition (e.g. cardiac arrhythmia, acute ischemic heart disease, need for vasoactive drugs); 2) known increased intracranial pressure; 3) small diameter endotracheal tube $(<7 \mathrm{~mm}) ; 4)$ acute respiratory distress syndrome (ARDS); 5) cerebral injury; or 6) coagulation's disorders. The study was approved by Ethical Committee of our Centre and in each case informed consent was obtained from the next of kin.

\section{Protocol}

The following demographic, clinical, and laboratory data were recorded from all patients: age; gender; underlying disease; cause of RICU admission; duration of mechanical ventilation before the study; use of corticosteroids (any i.v. administration during $24 \mathrm{~h}$ prior to sampling); prior antibiotic use (administered i.v. for more than $24 \mathrm{~h}$ ); blood analyses necessary for calculations of the simplified acute physiology score (SAPS II) [7]. Antipyretic medication (e.g. nonsteroid anti-inflammatory drugs) was not used $24 \mathrm{~h}$ prior to the study and was also withheld during the $24 \mathrm{~h}$ follow-up period.

Arterial oxygenation expressed as arterial partial pressure of oxygen/inspired fraction of oxygen $\left(\mathrm{Pa}, \mathrm{O}_{2}\right)$ $\left.F \mathrm{I}, \mathrm{O}_{2}\right)$, arterial blood pressure, cardiac frequency $\left(f_{\mathrm{C}}\right)$ and axillary body temperature were sequentially recorded and for the purpose of this study were documented before and at $12 \mathrm{~h}$ and $24 \mathrm{~h}$ after BAL. An increase in body temperature of $\geqslant 1{ }^{\circ} \mathrm{C}$ within the $24 \mathrm{~h}$ follow-up was defined as significant.

\section{Blood sampling}

Arterial blood samples were collected anaerobically, through an indwelling polyethylene catheter (Seldicath, Plastimed; Saint-Leu-La-Fôret, France) inserted into the radial artery, before, $12 \mathrm{~h}$ and $24 \mathrm{~h}$ after BAL, for blood gas and cytokine analyses. These time points were selected because in previous observations, serum tumour necrosis factor-alpha (TNF- $\alpha)$ levels after a fibreoptic procedure were detectable as early as $4 \mathrm{~h}$ after the procedure, peaked at $24 \mathrm{~h}$, and returned to undetectable levels by 48 h [8]. Samples for blood gases were immersed in ice and processed within $5 \mathrm{~min}$ in a blood gas analyser (ABL77 Radiometer, Copenhagen, Denmark). Cytokine samples were collected in sterile tubes without additive and after clotting, were centrifuged at $3.5 \times g$ for $10 \mathrm{~min}$. Serum was aspirated and stored at $-70^{\circ} \mathrm{C}$ until processing. Venous blood samples drawn before and $12 \mathrm{~h}$ and $24 \mathrm{~h}$ after BAL, were cultured for bacterial and fungal pathogens according to standard methods [9].

\section{Bronchoalveolar lavage ( $B A L)$}

Patients were sedated before the fiberoptically guided BAL (Pentax FB18, Asahi Optical Ltd., Japan). No local anaesthetics were administered and suction was carefully avoided until the bronchoscope had been wedged in the designated position. A special endotracheal adapter was used in order to continue mechanical ventilation. Patients were ventilated with volume control during bronchoscopy and ventilator settings were readjusted to pre-BAL values thereafter. During bronchoscopy $\mathrm{FI}, \mathrm{O}_{2}$ was set to $100 \%$ and reduced according to clinical conditions after $1 \mathrm{~h}$. Up to five aliquots of $30 \mathrm{~mL}$ physiologic saline were instilled (range $90-150 \mathrm{~mL}$ ) and the first aspirated portion was discarded. BAL fluid was subjected to microbiological analyses and only pathogens known to cause respiratory infections (potentially pathogenic micro-organisms, PPMs) are reported here.

\section{Cytokine assays}

The following cytokines were determined: TNF- $\alpha$, interleukin-1 $\beta$ (IL-1 $\beta$ ) and interleukin-6 (IL-6). Solid phase enzyme-linked immunosorbent assay (ELISA) was employed, based on the quantitative immunometric sandwich enzyme immunoassay technique on a microtitre plate (EASIA: Enzyme Amplified Sensitivity Immunoassay, Medgenix Diagnostics SA, Fleurus, Belgium). This ELISA method used a murine monoclonal antibody specific for the particular cytokine to be analysed, coated onto the microtitre plate to create the solid phase. Serum specimens were pipetted into the wells in duplicate. After the cytokine was bound to the immobilised antibody, a second monoclonal antibody was added to the wells and allowed to bind to a different epitope on the same cytokine. Horseradish peroxidase enzyme was conjugated to the monoclonal antibody. After an incubation period, a sandwich was formed. The enzyme substrate chromagen tetramethylbenzidine was then added and colour developed in proportion to the amount of the particular cytokine bound to the plate. Colour development was stopped with $\mathrm{H}_{2} \mathrm{SO}_{4}$, and colourimetric determination was done by means of a polychromic reader (EASIA Reader, Medgenix Diagnostics SA, Fleurus, Belgium). Concentrations of cytokines from samples were determined by comparing the optical densities of the samples to the standard curves. Results are expressed as $\mathrm{pg} \cdot \mathrm{mL}^{-1}$ of serum. The sensitivity of the technique allows the detection of levels as low as $3 \mathrm{pg} \cdot \mathrm{mL}^{-1}$ for TNF- $\alpha$ and $2 \mathrm{pg} \cdot \mathrm{mL}^{-1}$ for IL-1 $\beta$ and IL-6, respectively. The following values are regarded as upper limits for cytokine concentrations in normal controls in our laboratory: IL-6 $5 \mathrm{pg} \cdot \mathrm{mL}^{-1}$; TNF- $\alpha 20 \mathrm{pg} \cdot \mathrm{mL}^{-1}$; and IL-1 $\beta 15 \mathrm{pg} \cdot \mathrm{mL}^{-1}$.

\section{Statistical analysis}

Results are expressed as median and range because of the nonparametric distribution of the data. The MannWhitney U-test was employed for the comparison of 
quantitative variables between two groups. Changes over time were assessed by Wilcoxon test for paired differences. Proportions were compared by Chisquared test or Fisher's exact test where appropriate. The level of significance was set to $p \leqslant 0.05$ for all analyses (all two-tailed).

\section{Results}

A total of 30 patients were included in the study, 20 $(67 \%)$ with pneumonia according to the predefined criteria and 10 control patients without pneumonia $(33 \%)$ (table 1). Pneumonia was nosocomial in $12 / 20$ patients $(60 \%)$ and community acquired in $8 / 20$ patients $(40 \%)$. All 20 patients with pneumonia and 8 without pneumonia had received antibiotic drugs prior to BAL. Antibiotics were indicated in control patients for extrapulmonary infections or perioperative infection prophylaxis. Underlying diseases in the pneumonia group included cardiac disease $(n=4)$, chronic obstructive pulmonary disease (COPD, $n=5)$, stroke $(n=2)$, miscellaneous $(n=6)$, and none $(n=3)$. In the control group underlying diseases included: COPD $(n=5)$, miscellaneous $(n=3)$, and none $(n=2)$. Corticosteroid medication had been given to $16 / 30(53 \%)$ patients prior to the sampling procedure, mainly for bronchial dilatation, without significant differences between patients with pneumonia and controls (table 1). Within the pneumonia group, methylprednisolone had been given for a median $7.5(1-18)$ days in a median cumulative dose of $550(160-1605) \mathrm{mg}$. The median duration of therapy was $5(3-8)$ days in the control group $(\mathrm{p}=0.859)$ and the median cumulative dose of $360(160-705) \mathrm{mg}(\mathrm{p}=0.440)$. The mortality observed during RICU stay was 43\% (13/30 patients), with a slightly higher mortality among patients with pneumonia $(10 / 20,50 \%$ versus $3 / 10,30 \% \mathrm{p}=0.297)$.

Microbiological data were available in $18 / 20(90 \%)$ patients with pneumonia and all controls. A total of $7 /$ $18(39 \%)$ specimens were sterile. The following PPMs were recovered in the group of patients with pneumonia: Pseudomonas aeruginosa $(\mathrm{n}=2)$, Acinetobacter baumanii $(\mathrm{n}=1)$, Enterobacter spp. $(\mathrm{n}=2)$, Staphylococcus aureus $(\mathrm{n}=2)$, Streptococcus pneumoniae $(\mathrm{n}=2)$, and Aspergillus fumigatus $(\mathrm{n}=2)$. BAL cultures of control patients without pneumonia were sterile or

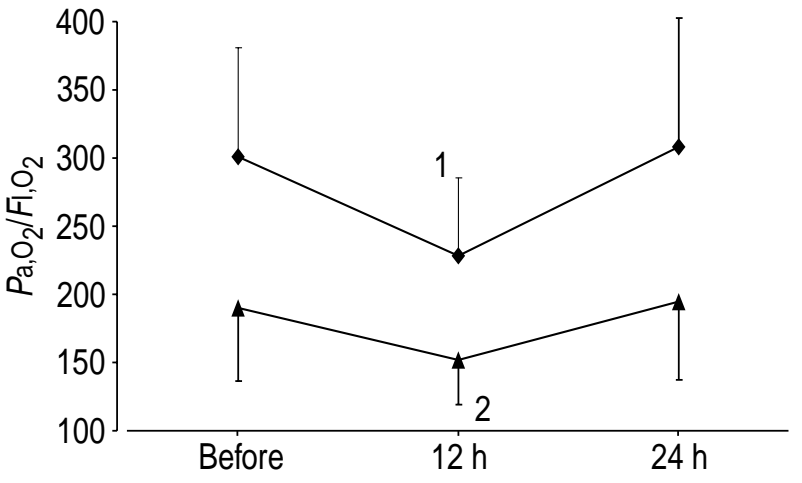

Fig. 1. - Variation of the arterial oxygen partial pressure to inspired oxygen fraction ratio $\left(P \mathrm{a}, \mathrm{O}_{2} / F \mathrm{I}, \mathrm{O}_{2}\right)$ over time in patients with $(\boldsymbol{\Delta} ; \mathrm{n}=20)$ and without (controls; $\boldsymbol{\nabla} \mathrm{n}=10)$ pneumonia after bronchoalveolar lavage (BAL). Data are presented as means and SDs. ${ }^{1}: \mathrm{p}=0.017{ }^{2}: \mathrm{p}=0.001$. ( $\mathrm{p}$-values are versus pre-BAL using Wilcoxon's test for paired differences).

showed no growth for PPMs in $8 / 10$ cases $(80 \%)$. One BAL showed growth for $P$. aeruginosa and $S$. aureus, respectively.

Blood cultures were sterile in all but one patient (29/ $30,97 \%$ ). The pre-BAL blood culture was negative in this particular patient with nosocomial pneumonia, whereas follow-up blood cultures at $12 \mathrm{~h}$ and at $24 \mathrm{~h}$ showed growth for Streptococcus epidermidis. This micro-organism was also isolated in the BAL fluid of the patient.

\section{Clinical variables}

The variation of the $P \mathrm{a}, \mathrm{O}_{2} / \mathrm{FI}, \mathrm{O}_{2}$ ratio over time for patients with pneumonia and control patients is summarized in figure 1 . The $P \mathrm{a}_{2} \mathrm{O}_{2} / F \mathrm{I}, \mathrm{O}_{2}$ ratio dropped significantly in both groups after the BAL and was significantly lower at $12 \mathrm{~h}$ compared to baseline. However, $\mathrm{Pa}, \mathrm{O}_{2} / F \mathrm{I}, \mathrm{O}_{2}$ ratio was indistinguishable from baseline at $24 \mathrm{~h}$ (fig. 1 ). The $\mathrm{Pa}_{\mathrm{a}} \mathrm{O}_{2} / \mathrm{FI}, \mathrm{O}_{2}$ ratio was significantly lower in patients with pneumonia compared to controls at any time point $(\mathrm{p}=0.001$, all time points).

The comparison between patients with pneumonia and controls for mean arterial pressure (MAP), axillary

Table 1. - Clinical data of patients investigated

\begin{tabular}{|c|c|c|c|}
\hline & With pneumonia $(\mathrm{n}=20)$ & Without pneumonia $(\mathrm{n}=10)$ & p-value \\
\hline Age yrs & $66.5(53-76)$ & $67.5(54-76)$ & 0.643 \\
\hline Gender male, $\mathrm{n}(\%)$ & $17(85)$ & $8(80)$ & 1.0 \\
\hline SAPS II & $33(12-52)$ & $30(18-56)$ & 0.983 \\
\hline$P \mathrm{a}, \mathrm{O}_{2} / F \mathrm{I}, \mathrm{O}_{2}$ & $192(65-256)$ & $293(205-473)$ & 0.001 \\
\hline Duration of mechanical ventilation prior to the study, $h$ & $52(18-408)$ & $60(24-298)$ & 0.619 \\
\hline Leukocyte count, $\times 10^{9} \cdot \mathrm{L}^{-1}$ & $14.5(1.9-26.5)$ & $10.5(7.0-16.8)$ & 0.198 \\
\hline Corticosteroids, n (\%) & $11(55)$ & $5(50)$ & 1.0 \\
\hline Prior antibiotics, n $(\%)$ & $20(100)$ & $8(80)$ & 0.103 \\
\hline Mortality, n (\%) & $10(50)$ & $3(30)$ & 0.297 \\
\hline
\end{tabular}

All patients received mechanical ventilation during the study and pneumonia was defined according to clinical criteria. Data are presented as median (range) unless otherwise stated. ๆ: Mann-Whitney U-test and Chi-squared or Fisher's exact test for quantitative and categorical variables, respectively. SAPS II: simplified acute physiology score II; $P \mathrm{a}_{1} \mathrm{O}_{2} / F \mathrm{I}, \mathrm{O}_{2}$ : arterial oxygen partial pressure to inspired oxygen fraction ratio. 

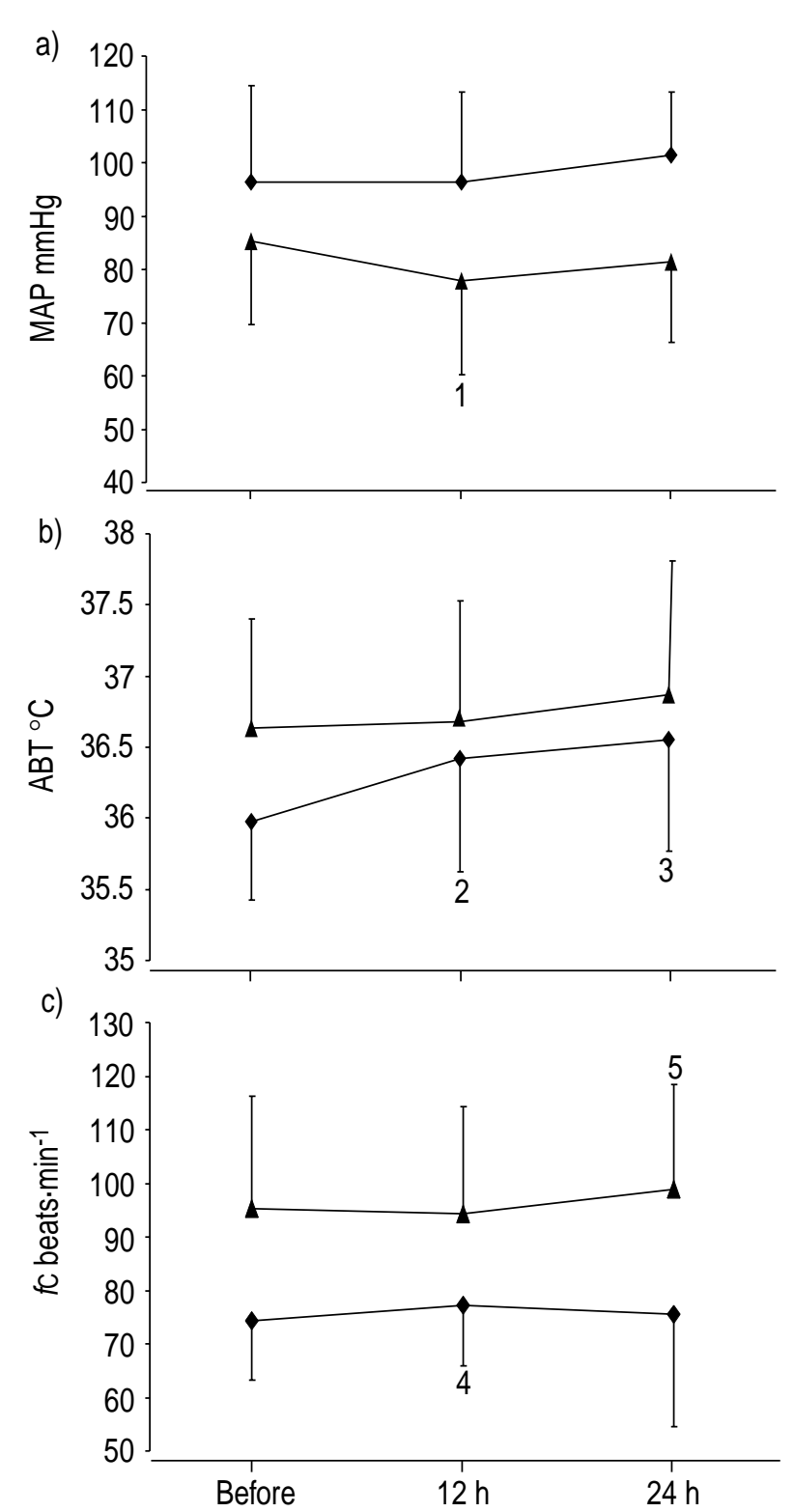

Fig. 2. - Comparison of changes in a) mean arterial blood pressure (MAP); b) axillary body temperature (ABT); and c) cardiac frequency $(f \mathrm{C})$ after bronchoalveolar lavage (BAL) in mechanically ventilated patients with $(\boldsymbol{\Delta} ; \mathrm{n}=20)$ and without (controls; $\checkmark ; \mathrm{n}=10)$ pneumonia. Date are presented as means and SDs. ${ }^{1}$ : $\mathrm{p}=0.07 ;{ }^{2}: \mathrm{p}=0.042{ }^{3}: \mathrm{p}=0.021 ;{ }^{4}: \mathrm{p}=0.194 ;{ }^{5}: \mathrm{p}=0.165$. (pvalues are versus pre-BAL using Wilcoxon's test for paired differences).

body temperature and $f \mathrm{C}$ are illustrated in figure 2 . The MAP tended to fall in patients with pneumonia during the first $12 \mathrm{~h}(\mathrm{p}=0.070)$, but increased again thereafter. No changes were observed in control patients during the follow-up period. A total of $7 / 30$ patients $(23 \%, 3$ patients with pneumonia and 4 controls) showed an increase of $\geqslant 1{ }^{\circ} \mathrm{C}$ in body temperature during followup. The MAP was different at baseline between patients with pneumonia and controls $(\mathrm{p}=0.172)$, but was significantly higher in controls at $12 \mathrm{~h}(\mathrm{p}=0.004)$ and at $24 \mathrm{~h}(\mathrm{p}=0.001)$, compared to patients with pneumonia.

Axillary body temperature increased significantly, only in control patients at $12 \mathrm{~h}(\mathrm{p}=0.042)$ and $24 \mathrm{~h}$ after BAL ( $p=0.021$; fig. 2$)$. Mean values of axillary body temperature were only significantly different between patients with pneumonia and controls before BAL $(\mathrm{p}=0.01)$, but not at $12 \mathrm{~h}(\mathrm{p}=0.699)$ or $24 \mathrm{~h}$ ( $\mathrm{p}=0.410$; fig. 2$)$.

No significant changes were observed for $f \mathrm{C}$ after BAL, neither in patients with pneumonia or the control group (fig. 2). Patients with pneumonia had a higher average $f \mathrm{C}$ compared to control patients before $\mathrm{BAL}$ $(\mathrm{p}=0.005)$ and at $12 \mathrm{~h}(\mathrm{p}=0.009)$ and $24 \mathrm{~h}(\mathrm{p}=0.009)$ after BAL.

\section{Systemic cytokine levels}

Baseline levels of TNF- $\alpha$ and IL-6 were significantly higher in pneumonia patients compared to controls, reflecting the inflammatory process. However, systemic cytokine expression in serum did not change significantly after BAL in our patients. There was a trend for IL-1 $\beta$ to increase at $24 \mathrm{~h}$ and IL-6 tended to fall at this time point (table 2 ). These changes were caused mainly by the patients in the pneumonia group. The concentration of TNF- $\alpha$ and IL-6 in serum was higher in patients with pneumonia compared to control patients at all time points (table 2), but this was not the case for IL-1 $\beta$.

\section{Subanalysis}

Data were reanalysed according to the recovery of PPMs in the BAL, because all patients with pneumonia were pre-treated with antibiotics. The results are summarized in table 3 . No significant changes over time, or for the comparison of patients with and without pathogens in the lavage, were found.

Pneumonia patients and controls were analysed separately for the comparison of subjects with and without an increase of $\geqslant 1{ }^{\circ} \mathrm{C}$ in body temperature during follow-up, to avoid bias introduced by differences in baseline cytokine levels. Among control patients with an increase in body temperature, only serum IL-6 was significantly higher after $12 \mathrm{~h}$ compared to control patients without an increase in body temperature (with increase $81(51-159) \mathrm{pg} \cdot \mathrm{mL}^{-1}$, no increase $\left.17(12-55) \mathrm{pg} \cdot \mathrm{mL}^{-1}, \mathrm{p}=0.032\right)$. No significant differences for baseline cytokine levels were observed for this comparison. In patients with pneumonia, analysis revealed that those who developed an increase in body temperature showed significantly higher values of TNF- $\alpha 24 \mathrm{~h}$ after BAL (with increase 61 (59-63) $\mathrm{pg} \cdot \mathrm{mL}^{-1}$, no increase $\left.25(0-49) \mathrm{pg} \cdot \mathrm{mL}^{-1} \mathrm{p}=0.019\right)$.

In another subanalysis, cytokine levels were compared for patients with and without corticosteroid medication also separated for pneumonia patients and controls. In control patients, no differences were found for this comparison in either baseline cytokine levels or during follow-up. Among the patients with pneumonia, baseline serum levels of IL-6 were lower in patients with corticosteroids, compared to those without pneumonia at baseline (with corticosteroids $97(9-2600) \mathrm{pg} \cdot \mathrm{mL}^{-1}$, no corticosteroids $\left.914(35-4300) \mathrm{pg} \cdot \mathrm{mL}^{-1}, \mathrm{p}=0.031\right)$ 
Table 2. - Mean systemic cytokine levels before bronchoalveolar lavage (BAL), and $12 \mathrm{~h}$ and $24 \mathrm{~h}$ thereafter for all the patients and separately for patients with pneumonia and controls

\begin{tabular}{|c|c|c|c|}
\hline Concentration $\mathrm{pg} \cdot \mathrm{mL}^{-1}$ & Before BAL & $12 \mathrm{~h}$ & $24 \mathrm{~h}$ \\
\hline \multicolumn{4}{|l|}{ All patients $(n=30)$} \\
\hline TNF- $\alpha$ & $22(0-88)$ & $19(0-64)$ & $25(0-63)$ \\
\hline IL-1 $\beta$ & $0(0-32)$ & $0(0-31)$ & $2(0-122) *$ \\
\hline IL-6 & $108(0-4300)$ & $84(12-3778)$ & $112(5-1976)$ \\
\hline \multicolumn{4}{|l|}{ With pneumonia $(\mathrm{n}=20)$} \\
\hline $\mathrm{TNF}-\alpha$ & $35(10-88)$ & $35(0-64)$ & $31(0-36)$ \\
\hline IL- $1 \beta$ & $0(0-13)$ & $3(0-31)$ & $5(0-122)^{\#}$ \\
\hline IL-6 & $226(9-4300)$ & $156(16-3778)$ & $194(11-1976)$ \\
\hline \multicolumn{4}{|l|}{ Controls $(n=10)$} \\
\hline TNF- $\alpha$ & $17(0-33)$ & $15.5(0-21)^{\top}$ & $19(0-43)$ \\
\hline IL-1 $\beta$ & $1(0-32)$ & $0(0-13)^{+}$ & $0(0-7)$ \\
\hline IL-6 & $53(0-346)$ & $55(12-159)$ & $46(5-296)$ \\
\hline \multicolumn{4}{|c|}{ p-values ${ }^{\S}$ for comparison between patients with and controls } \\
\hline TNF- $\alpha$ & 0.010 & 0.002 & 0.037 \\
\hline IL-1 $\beta$ & $>0.2$ & $>0.2$ & $>0.2$ \\
\hline IL-6 & 0.017 & 0.021 & 0.074 \\
\hline
\end{tabular}

Values were compared at different time points and between patients with and without pneumonia (exact p-values are given if $\mathrm{p}<0.2$ ). Data are presented as median (range). TNF- $\alpha$ : tumour necrosis factor $\alpha$; IL: interleukin; *: $\mathrm{p}=0.150$ versus baseline; $\#: p=0.054$ versus baseline; ${ }^{\oplus}: \mathrm{p}=0.123$ versus baseline; ${ }^{+}: \mathrm{p}=0.068$ versus baseline; ${ }^{\S}$ : $\mathrm{p}$-value calculated with Mann-Whitney U-Test.

and at $12 \mathrm{~h}$ follow-up (with corticosteroids 78 $(16-2560) \mathrm{pg} \cdot \mathrm{mL}^{-1}$, no corticosteroids $982(33-3778)$ $\left.\mathrm{pg} \cdot \mathrm{mL}^{-1}, \mathrm{p}=0.041\right)$.

\section{Discussion}

The findings of this study do not support the hypothesis that pneumonia is a predisposing condition leading to development of a systemic inflammatory response after BAL. This conclusion is based on observations that; 1) bronchoscopically guided BAL in critically ill patients was not associated with clinically significant changes of MAP, body temperature or $f \mathrm{C}$ at $12 \mathrm{~h}$ or $24 \mathrm{~h}$, regardless of the presence of pneumonia; 2) there was no increase in systemic cytokine release after bronchoscopically guided BAL at $12 \mathrm{~h}$ and $24 \mathrm{~h}$ in either patients with pneumonia or in controls; 3) a systemic inflammatory response after BAL in patients with pneumonia did not depend on the presence or absence of bacterial pathogens in BAL fluid.

BAL is an important diagnostic tool in critically ill patients. The procedure is generally regarded as safe, and severe side effects rarely occur [3]. Most previous studies agree on the fact that BAL induces deterioration of arterial oxygenation [1,10-12], but these changes are of transient nature. This observation was confirmed in the present study, where all patients, regardless of whether they had pneumonia or not, showed a lower $P \mathrm{a}, \mathrm{O}_{2} / F \mathrm{I}, \mathrm{O}_{2}$ ratio at $12 \mathrm{~h}$, but returned to or above baseline at $24 \mathrm{~h}$ (fig. 1). However, apart from changes in gas exchange, bronchoscopically guided BAL may be followed by fever and other symptoms that have been summarized as sepsis-like effects. The mechanisms that

Table 3. - Comparison of clinical and cytokine data between patients with pneumonia and recovery of a potentially pathogenic micro-organism (PPM) in bronchoalveolar lavage (BAL), and patients with pneumonia and sterile BAL cultures

\begin{tabular}{|c|c|c|c|}
\hline & Before BAL & $12 \mathrm{~h}$ & $24 \mathrm{~h}$ \\
\hline \multicolumn{4}{|l|}{ PPM recovered $(\mathrm{n}=11)^{*}$} \\
\hline Mean arterial blood pressure, $\mathrm{mmHg}$ & $88(67-110)$ & $77(65-108)$ & $82(73-100)$ \\
\hline Axilliary body temperature, ${ }^{\circ} \mathrm{C}$ & $36.2(35.6-37.6)$ & $37.0(35.8-38.6)$ & $36.8(36.2-38.0)$ \\
\hline Cardiac frequency beats $\cdot \mathrm{min}^{-1}$ & $95(80-145)$ & $100(75-125)$ & $105(70-135)$ \\
\hline $\mathrm{TNF}-\alpha, \mathrm{pg} \cdot \mathrm{mL}^{-1}$ & $39(13-88)$ & $41(0-64)$ & $37.5(15-63)$ \\
\hline $\mathrm{IL}-1 \beta, \mathrm{pg} \cdot \mathrm{mL}^{-1}$ & $2(0-12)$ & $3(0-14)$ & $4(0-122)$ \\
\hline IL- $6, \mathrm{pg} \cdot \mathrm{mL}^{-1}$ & $297(47-4300)$ & $359(53-3778)$ & $194(23-924)$ \\
\hline \multicolumn{4}{|l|}{ BAL sterile or no PPM $(\mathrm{n}=7)^{*}$} \\
\hline Mean arterial blood pressure, $\mathrm{mmHg}$ & $68(57-107)$ & $70(57-110)$ & $73(62-112)$ \\
\hline Axilliary body temperature, ${ }^{\circ} \mathrm{C}$ & $37.2(35.8-38.0)$ & $36.4(35.8-38.0)$ & $36.8(35.0-38.8)$ \\
\hline Cardiac frequency beats $\cdot \mathrm{min}^{-1}$ & $85(60-115)$ & $90(50-105)$ & $85(80-110)$ \\
\hline $\mathrm{TNF}-\alpha, \mathrm{pg} \cdot \mathrm{mL}^{-1}$ & $22(10-47)$ & $25(14-44)$ & $23.5(0-48)$ \\
\hline $\mathrm{IL}-1 \beta, \mathrm{pg} \cdot \mathrm{mL}^{-1}$ & $0(0-13)$ & $2(0-31)$ & $4(0-43)$ \\
\hline IL-6, pg.mL $\mathrm{mL}^{-1}$ & $78(9-1424)$ & $53(16-1487)$ & $43(11-596)$ \\
\hline
\end{tabular}

Data are presented as median (range). TNF- $\alpha$ : tumour necrosis factor $\alpha$; IL: interleukin; PPM: potentially pathogenic microorganism. *: microbiological results were not available in $2 / 20(10 \%)$ patients with pneumonia. No significant differences were observed for the comparison between time points or between patients with and without recovery of a PPM. 
are associated with these sepsis-like symptoms are not known, although they may occur in as many as 30\% of the fibreoptically guided procedures [3]. Previous reports, however, suggested that the release of proinflammatory cytokines may be involved.

Pugin and SuTER [13] investigated clinical effects of a fibreoptically guided BAL in critically ill patients with and without pneumonia. They found a significant increase in body temperature and decrease in MAP after the procedure in patients with pneumonia but not in controls. Changes in body temperature correlated significantly with those in MAP, and also with the level of endotoxin in bronchoscopic BAL fluid. These findings suggested that BAL, in critically ill patients with pneumonia, may have caused intravascular translocation of toxins or mediators producing pyrogenic and hypotensive effects. The data from the present study supports this hypothesis only in part, because no general increase in the systemic inflammatory response, as measured by cytokine levels, could be found at $12 \mathrm{~h}$ or $24 \mathrm{~h}$. Similarly, no statistically or clinically significant changes in body temperature, MAP or $f C$ could be found after the bronchoscopically guided BAL. It is plausible that differences from the previous study are accounted for by the fact that all but two of our patients had received antibiotic treatment before sampling. Systemic cytokine release, associated with bacterial translocation, may have been blunted by this treatment. On the other hand, one might also argue that the increase in body temperature reported by Pugin and Suter [13] was less likely due to the diagnostic procedure, but due to pneumonia. However, when patients with and without an increase in body temperature $\geqslant 1{ }^{\circ} \mathrm{C}$ during the follow-up period were compared, an increase in IL-6 in control patients after $12 \mathrm{~h}$ was seen that was no longer significant after $24 \mathrm{~h}$. It is likely that a transient inflammatory response was described in this subgroup of patients without pneumonia, that may have been associated with the diagnostic procedure. This should be confirmed, though, in a larger cohort, because the number of control patients in the present study was small, and the definition of a temperature increase had to be arbitrary.

A significant systemic cytokine release after BAL has been observed in previous studies involving noncritically ill patients. In a report of a normal healthy volunteer who underwent bronchoscopy and BAL, STANDIFORD et al. [8] showed rising TNF- $\alpha$ levels associated with clinical symptoms after the intervention. KRAUSE et al. [4] systematically compared the systemic inflammatory response after bronchoscopy with and without BAL in 50 patients, with a variety of pulmonary conditions including pulmonary metastasis or bronchial carcinoma. They found an increase of systemic levels of IL- $1 \beta$ and IL- 6 at $6 \mathrm{~h}$ in all patients, although the increase seemed to be more pronounced in the BAL group. Baseline cytokine levels, however, were low in this noncritically ill population and the mean increase was $27.5 \mathrm{pg} \cdot \mathrm{mL}^{-1}$ for IL-6. Regarding the present study in critically ill patients, an increase of this magnitude was not detectable, and probably not clinically important, because e.g. the IL-6 median level was already more than 30 -fold at baseline $\left(108 \mathrm{pg} \cdot \mathrm{mL}^{-1}\right)$ compared to the baseline median
(3.71 $\left.\mathrm{pg} \cdot \mathrm{mL}^{-1}\right)$ reported in the study by KRAUSE et al. [4] (table 2). In addition, TNF- $\alpha$ levels and particularly IL-6 levels were already well above the normal upper limits for healthy controls at baseline.

This study included one case of possible translocation of $S$. epidermidis from the pulmonary compartment to the bloodstream after BAL in a 74-yr old female with bilateral nosocomial pneumonia, who had been on mechanical ventilation with zero positive endexpiratory pressure (PEEP) for more than $24 \mathrm{~h}$. Bacteraemia has been described after rigid bronchoscopy, but has never been documented after fibreoptic procedures in humans [4, 14]. Animal data suggest that this route of dissemination may have been facilitated by mechanical ventilation [6] or injury to the alveolar epithelium [15]. VerbrugGe et al. [16] determined the effect of PEEP on the development of bacteraemia with Klebsiella pneumoniae after mechanical ventilation of intratracheally inoculated rats, and concluded that $10 \mathrm{cmH}_{2} \mathrm{O}$ PEEP reduced ventilation-induced $K$. pneumonia bacteraemia. Nevertheless, a causal relationship to the fibreoptic procedure cannot be confidently assumed from the present study, since bacteraemia is a common finding in patients with nosocomial pneumonia, or it may have occurred spontaneously [17]. In addition, $S$. epidermidis is not a common nosocomial pathogen and the assumed translocation from alveolar space to bloodstream may have been unrelated to the underlying inflammatory process. Furthermore, when the systemic inflammatory response was analysed with respect to the presence or absence of potentially pathogenic micro-organisms in the BAL fluid, no significant differences in the systemic inflammatory response after bronchoscopically guided BAL were found.

One might argue that this study simply missed the increase in the systemic inflammatory response, because only two time points were assessed ( $12 \mathrm{~h}$ and $24 \mathrm{~h}$ ). However, Krause et al. [4] observed differences at $6 \mathrm{~h}$ and the well documented case report suggested a peak response at $24 \mathrm{~h}$. However, it cannot be ruled out that short-term changes were missed due to the study design, or changes in the local inflammatory response because patients were not investigated with a follow-up bronchoscopy. A major confounding factor in this study was probably the antibiotic treatment. In fact a trend was even observed towards lower IL-6 levels at $24 \mathrm{~h}$, which could possibly reflect the adequacy of treatment and the decreasing systemic inflammatory response. Nevertheless, it is important not to extrapolate the results to a population without pre-emptive antibiotic therapy. To assist bronchodilatation, a considerable proportion of the patients had received corticosteroids prior to the study, which have been shown to interfere with cytokine levels [18]. The comparison between patients with and without corticosteroid treatment was hampered by substantial differences in cytokine levels at baseline between patients with pneumonia and controls, as it has been described previously [18]. A multivariate analysis would have been interesting to separate effects of BAL and corticosteroids on cytokine kinetics. However, the present study was too small to allow a reasonable application of this statistical method. 
In conclusion, whereas bronchoscopically guided bronchoalveolar lavage seems to be associated with a clinically significant systemic cytokine release in the noncritically ill patient, no general confirmation of this finding in a population of intubated and mechanically ventilated patients could be made. One possible explanation may be that the magnitude of the induced systemic inflammatory response may be insignificant in critically ill patients with high baseline cytokine levels. A transient increase in interleukin-6 levels was observed among patients without pneumonia after $12 \mathrm{~h}$ when patients with and without an increase in body temperature were compared, but limitations apply to this subanalysis. Future trials should assess whether antibiotic or corticosteroid pre-treatment has any effect on the systemic inflammatory response after bronchoscopic procedures.

\section{References}

1. Hertz MI, Woodward ME, Gross CR, Swart M, Marcy TW, Bitterman PB. Safety of bronchoalveolar lavage in the critically ill, mechanically ventilated patient. Crit Care Med 1991; 19: 1526-1532.

2. Montravers P, Gauzit R, Dombret MC, Blanchet F, Desmonts JM. Cardiopulmonary effects of bronchoalveolar lavage in critically ill patients. Chest 1993; 104: $1541-1547$.

3. Klech H, Pohl W, Hutter C. Safety and side-effects of bronchoalveolar lavage. Eur Respir Rev 1992; 2: $54-$ 57.

4. Krause A, Hohberg B, Heine F, John M, Burmeister GR, Witt C. Cytokines derived from alveolar macrophages induce fever after bronchoscopy and bronchoalveolar lavage. Am J Respir Crit Care Med 1997; 155: $1793-1797$.

5. Chastre J, Trouillet JL, Vuagnat A, et al. Nosocomial pneumonia in patients with acute respiratory distress syndrome. Am J Respir Crit Care Med 1998; 157: $1165-1172$.

6. Nahum A, Hoyt J, Schmitz L, Moody J, Shapiro R, Marini JJ. Effect of mechanical ventilation strategy on dissemination of intratracheally instilled Escherichia coli in dogs. Crit Care Med 1997; 25: 1733-1743.

7. Le Gall JR, Lemeshow S, Saulnier F. A new simplified acute physiology score (SAPS II) based on a
European/North American multicenter study. JAMA 1993; 270: $2957-2963$.

8. Standiford TJ, Kunkel SL, Strieter RM. Elevated serum levels of tumor necrosis factor-a after bronchoscopy and bronchoalveolar lavage. Chest 1991; 99: 1529-1530.

9. Lennette EH, Bullows A, Hausler WJ, Sadhomy HJ. Manual of clinical microbiology. 4th: Washington, American Society for Microbiology, 1985.

10. Papazian L, Colt HG, Scemama F, Martin C, Gouin F. Effects of consecutive protected specimen brushing and bronchoalveolar lavage on gas exchange and hemodynamics in ventilated patients. Chest 1993; 104: $1548-1552$.

11. Kollef MH, Bock KR, Richards RD, Hearns ML. The safety and diagnosis accuracy of minibronchoalveolar lavage in patients with suspected ventilator associated pneumonia. Ann Intern Med 1995; 122: 743-748.

12. Steinberg KP, Mitchell DR, Maunder RJ, Milberg JA, Whitcomb ME, Hudson LD. Safety of bronchoalveolar lavage in patients with adult respiratory distress syndrome. Am Rev Respir Dis 1993; 148: 556- 561.

13. Pugin J, Suter PM. Diagnostic bronchoalveolar lavage in patients with pneumonia produces sepsis-like systemic effects. Intensive Care Med 1992; 18: 6-10.

14. Kane RC, Cohen MH, Fossieck BEJ, Tvardzik AV. Absence of bacteremia after fiberoptic bronchoscopy. Am Rev Respir Dis 1975; 111: 102-104.

15. Kurahashi K, Kajikawa O, Sawa T, et al. Pathogenesis of septic shock in Pseudomonas aeruginosa pneumonia. J Clin Invest 1999; 104: $743-750$.

16. Verbrugge SJ, Sorm V, van't Veen A, Mouton JW, Gommers D, Lachmann B. Lung overinflation without positive end-expiratory pressure promotes bacteremia after experimental Klebsiella pneumoniae inoculation. Intensive Care Med 1998; 24: 172-177.

17. Vallés J, León C, Alvarez-Lerma F. Nosocomial bacteremia in critically ill patients: a multicenter study evaluating epidemiology and prognosis. Spanish Collaborative Group for Infections in Intensive Care Units of Sociedad Espanola de Medicina Intensiva y Unidades Coronarias (SEMIUC). Clin Infect Dis 1997; 24: 387-395.

18. Montón C, Ewig S, Torres A, et al. Role of glucocorticoids on inflammatory response in nonimmunosuppressed patients with pneumonia: a pilot study. Eur Respir J 1999; 14: 218-220. 